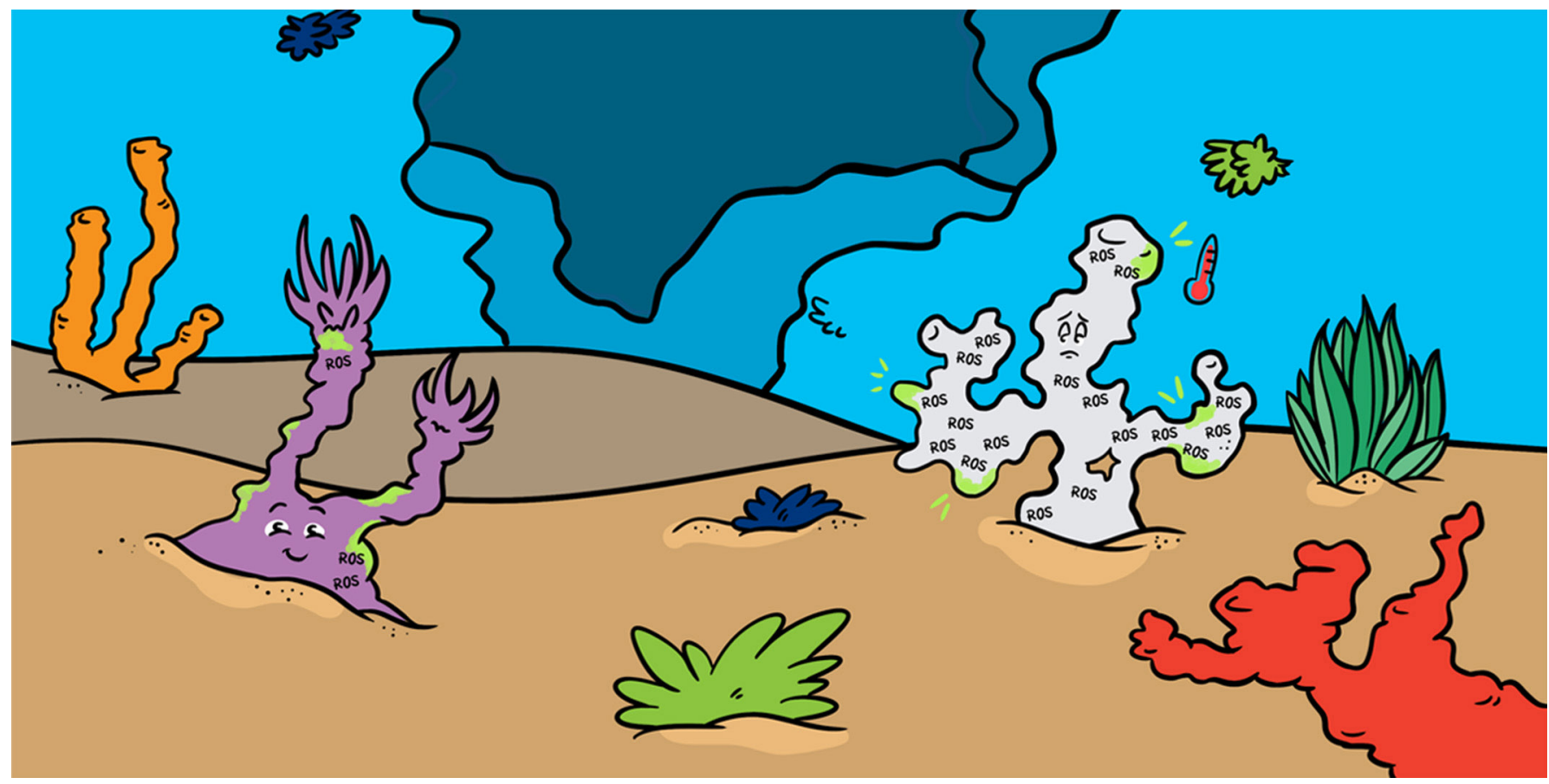

\title{
WITH A LITTLE HELP FROM FRIENDS-HOW ALGAE HELP CORALS SURVIVE TEMPERATURE STRESS
}

\section{Maha Joana Cziesielski* and Manuel Aranda}

Red Sea Research Center, King Abdullah University of Science and Technology, Thuwal, Saudi Arabia

\section{YOUNG REVIEWERS:}

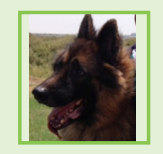

ARNAB

AGE: 14

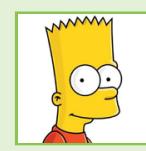

EVAN

AGE: 12

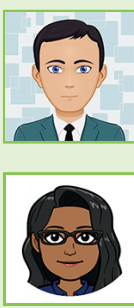

SUBHAAN

AGE: 13

VARSHINI

AGE: 14

\section{INVERTEBRATES}

Animals that lack a backbone, or spine, like snails or jellyfish.
Have you ever been in the ocean and admired the many fish living on the reef? Did you notice the colorful rock-like structures? Those colorful rocks are actually animals called corals. Corals are the building blocks of reefs and provide homes for many marine species. However, corals are very sensitive to changes in the environment. Human impact has caused our oceans to become warmer. Corals are struggling to survive. But there is hope: some corals have learned to live in warm waters, such as the Red Sea, and in places with hot summers. This shows us that there is a chance for corals to survive. We studied Red Sea corals and found that they have adapted to warmer waters using specific mechanisms, and some help from their algae friends. By learning what makes some corals stronger, we can hopefully figure out a way to help the weaker corals.

\section{THE SENSITIVE LIFE OF CORALS}

Corals are invertebrate animals that belong to the same group as jellyfish and anemones. Corals have a bone-like skeleton that sets them 


\section{ANEMONE}

Is a close relative of corals. Anemones have a similar structures and lifestyle as corals but are squishier. Aiptasia is an anemone.

\section{ALGAE}

A very simple, waterbased plant, like seaweed.

\section{SYMBIODINIACEAE}

Is a type of algae.

\section{SYMBIOSIS}

The interaction or relationship between two different organisms living closely together, typically providing an advantage to both.

\section{Figure 1}

The relationship between DNA, RNA, and protein. DNA contains all the information required for the production of proteins, which perform many important functions in each cell. To make a protein, the cell can access the information it needs by first turning DNA into RNA, through a process called transcription. Then the RNA will be turned into the proper protein through a process called translation.

apart from their other family members. Corals live together with small algae, called Symbiodiniaceae. The coral and algae help each other survive. This is known as living in symbiosis. The coral gives the algae protection and the algae gives the coral the energy to build a large skeleton [1].

When there are too many changes in the environment, the coral and algae get stress and cannot communicate well. They then stop helping each other and the algae will leave the coral. Because the beautiful colors of coral come from algae, when the algae leave, the coral turns white. This is what we know as coral bleaching. One of the main reasons for coral and algae breaking up is warmer temperatures. Warmer water temperatures stress out the coral and the algae and lead to bleaching. Climate change and other human impacts have increased ocean temperatures worldwide. Every year, coral reefs are experiencing hotter summers. How much heat can our coral reefs survive?

\section{LOOKING INSIDE CELLS TO FIND CORAL'S SECRETS}

Before corals bleach, they do not show many other signs of feeling stressed. So, if we want to understand a coral's health, we have to study its cells. Inside cells we have a lot of information, including DNA, RNA, and proteins. These molecules can help us find clues about the communication between the coral and the algae. But also, these molecules can teach us how to know when corals are stressed.

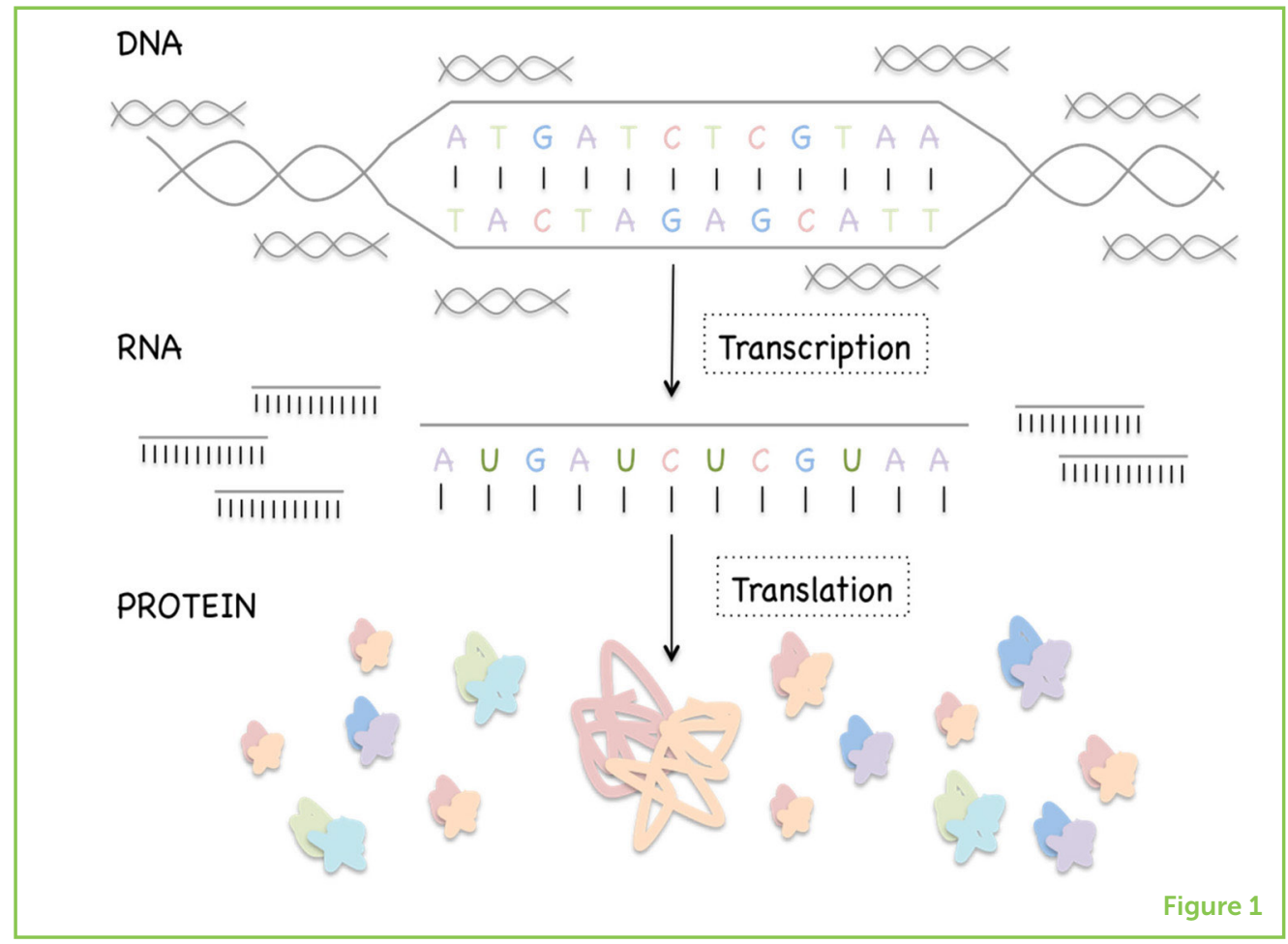




\section{ADAPTATION}

Is to adapt, meaning to make yourself more fit to survive.

Figure 2

Annual average temperatures of the three locations from which the anemone Aiptasia was studied. These anemones were taken from North Carolina (green), Hawaii (blue), and the Red Sea (red). The average monthly temperature is shown by a solid line. Shading around the line shows the maximum and minimum temperatures. This data shows that the Red Sea has the warmest waters [2] (temperature data obtained from www. seatemperature.org).
When an organism is stressed, every cell in its body will react. Everything will do its best to survive! In response to stress, the cell will use its DNA to make RNA, so that it can then make proteins that will fight off the stress (Figure 1). If an organism has been stressed before, it can respond to the stress faster and better. Think of it like visiting a city: the first time you visit, you will need a map to find your hotel. The more often you visit the city, the less you will need the map because you will remember, and you will get back to the hotel faster. Corals that have been in hot water before remember how to best survive. We can see this memory in the cells. The cells that have been stressed in the past will begin making different proteins and make the right proteins faster. So, they respond in a way that is different from corals that have never been in hot water before. Studying these difference lets us see what makes certain corals able to survive heat while others cannot.

\section{STUDYING CORALS THAT ARE GOOD AT COPING WITH HIGHER TEMPERATURES}

Corals can have different resistance to warm temperatures. The environment the corals grow up in can influence their behavior. Many species of coral have learned to live in the world's warmest waters, such as the Red Sea or the Arabian Gulf. This shows that corals are able to adapt to more stressful environments. To learn what makes some corals tougher than others, we used a model organism: the small sea anemone Aiptasia. Anemones are related to coral, but Aiptasia is easier to study than coral, because it grows fast and has no skeleton. We wanted to understand what allows some animals to deal better than others with warm temperatures. What do those animals do differently to survive

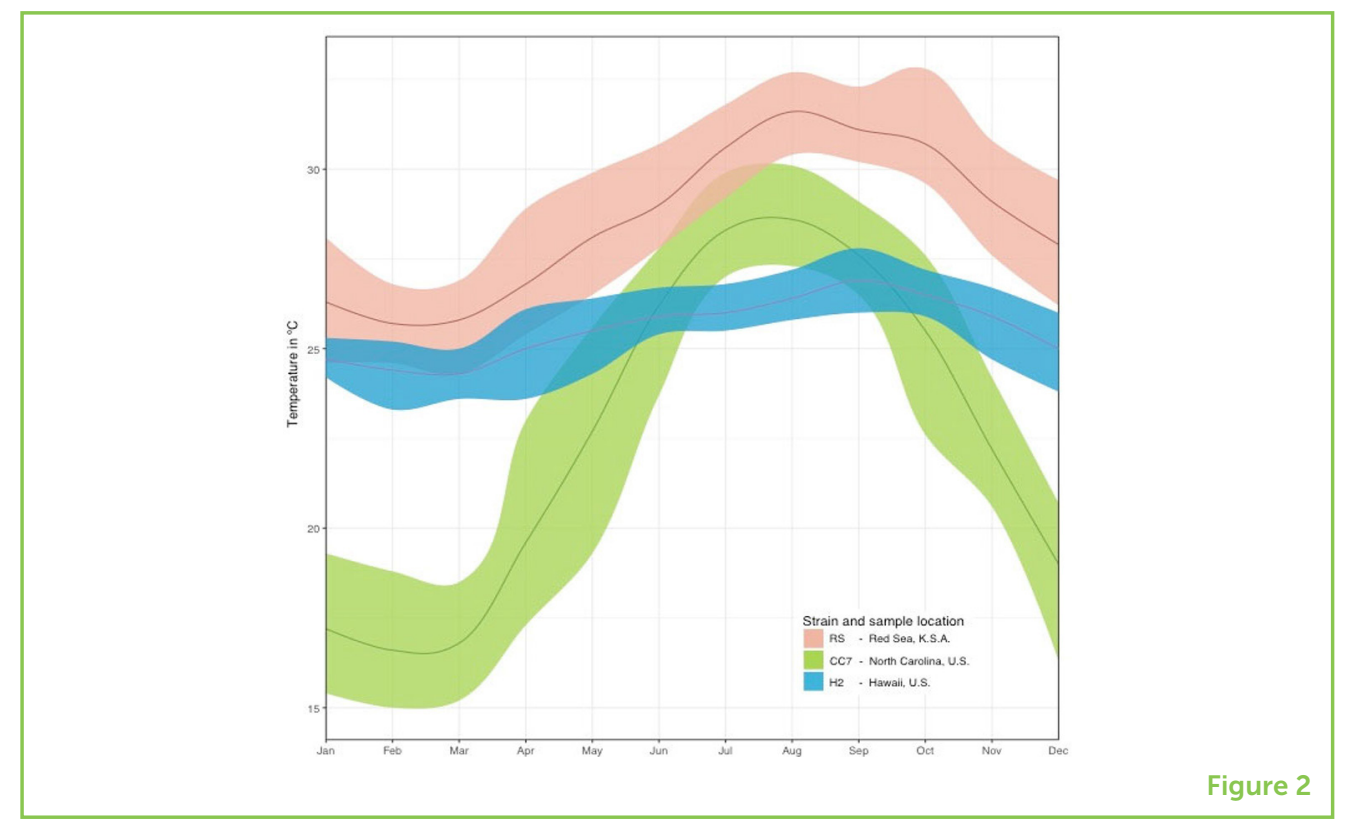


REACTIVE OXYGEN SPECIES (ROS)

A chemical compound that is released during cellular respiration, which can be toxic if not removed by the cell. the heat? For this we studied Aiptasia from different places around the world: North Carolina, Hawaii, and the Red Sea (Figure 2).

We took anemones from each location and kept them at the same temperature of $25^{\circ} \mathrm{C}$ for more than 1 year. Then, for some anemones, we slowly heated the water to $32^{\circ} \mathrm{C}$. Anemones were heat stressed for $24 \mathrm{~h}$. After that, we took cells from all anemones to compare their stress levels and responses. Studying the RNA and proteins in the anemones' cells allowed us to compare how different anemones cope with temperature.

\section{REMOVING TOXIC CHEMICALS TO SURVIVE HEAT STRESS}

When organisms become stressed, they produce a number of toxic chemicals. Most of the time, each cell in the body can remove the chemicals before they become dangerous. Sometimes, especially when there is too much stress, cells will fail to remove the stress chemicals. Then, those chemicals will build up until they become toxic and cause serious damage to the cells. One common chemical that increases in response to stress is called reactive oxygen species (ROS).

ROS is a normal side product of cellular respiration, which is scientific term for the way cells generate the energy they need to live. Stress increases the amount of energy generated by cells, which also increases the levels of ROS. Because too much ROS is so toxic, ROS has been linked to bleaching of the anemones, just like in corals. An even bigger problem is that the anemone not only has to deal with its own ROS, but also ROS from the algae that live with it. The algae can pass their ROS on to anemones [3]. This increases the overall toxic level of ROS in the anemones. An anemone that can properly remove ROS even when it is stressed can cope better with high temperatures than anemones that have trouble removing ROS. We compared the ROS levels between our three anemones before and after heat stress. The Red Sea anemone had the lowest ROS levels. This result told us that Red Sea anemones can survive in the warm waters because they can remove toxic chemicals, like ROS, faster than other anemones can. Since anemones are related to corals, it is very likely that this process of removing toxic chemicals can keep corals healthy in warmer waters, too.

\section{ALGAE HELP ANEMONES ADAPT TO TEMPERATURE}

We know that the algae can pass ROS to anemones. So, the more stressed the algae are, the more stressed the anemone will be. In complex system like the coral reef, we cannot study one partner without the other. 
Figure 3

ROS produced by Symbiodiniaceae, the algae that live together with coral and anemones.

(A) Symbiodiniaceae that lives inside anemones was tested for levels of ROS at both the normal temperature of $25^{\circ} \mathrm{C}$ and the heat stress temperature of $32^{\circ} \mathrm{C}$. (B) Symbiodiniaceae that lives outside anemones was tested the same way. The stars between the temperatures of an anemone show where the change in ROS levels was strong. The data show that the algae that live in the Red Sea anemones had the least amount of ROS production in all conditions [2]. This means that the Red Sea anemone and algae were the least stressed when temperatures increased.

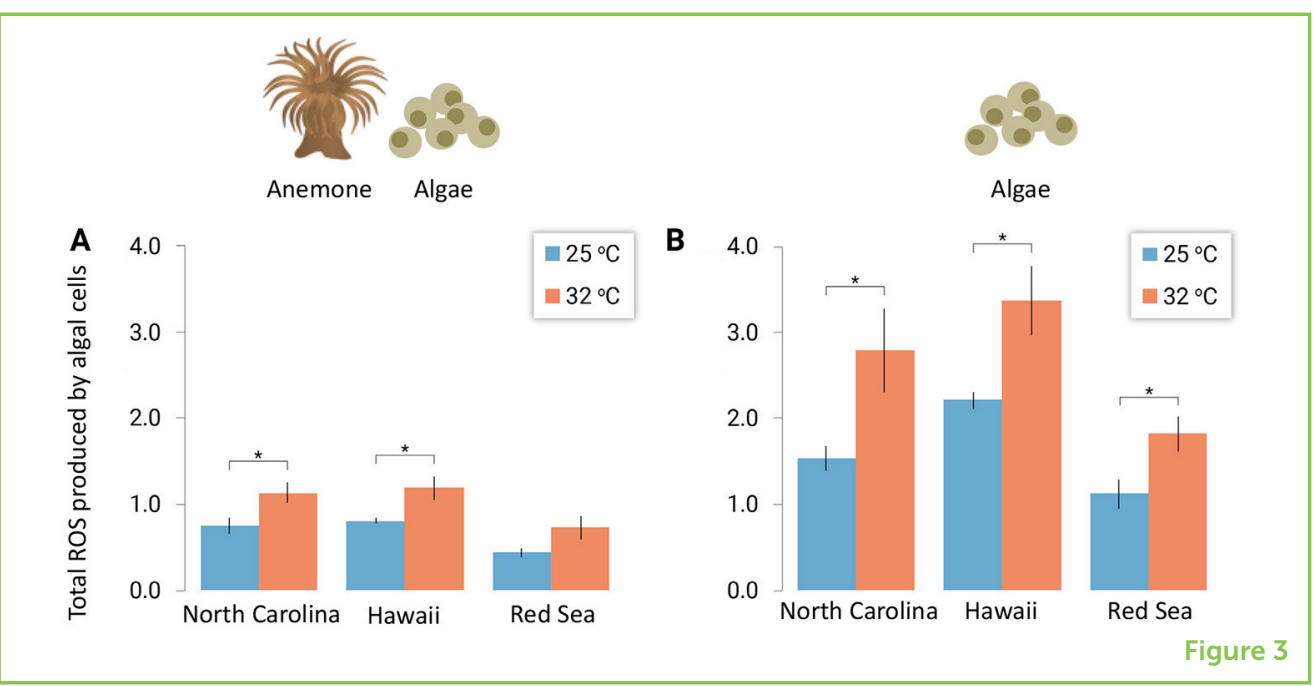

We saw that the Red Sea anemones survived in warmer water because they were able to quickly remove toxic chemicals. Next, we needed to understand if the algae were helping the anemones or harming them. We measured the concentration of ROS produced by the algae when it was living inside the anemone vs. when it was living outside the anemone (Figure 3).

In the Red Sea anemones, we saw less ROS in the algae living both inside and outside of the anemones. This meant that the algae from the Red Sea were less stressed by the warm temperatures than were algae that lived with the anemones from North Carolina or Hawaii. By dealing with the stress better, the algae produced less ROS. That meant that less ROS was sent to the anemone, and so both organisms had fewer toxic chemicals to deal with, overall. The Red Sea anemone therefore experienced less stress than the anemones from the other regions. The levels of ROS from the algae in other anemones showed us that other algae are more sensitive to heat (Figure 3). We can see that algae can help the anemones, and therefore also corals, cope better with high temperatures.

\section{ANEMONES AND ALGAE ARE IN THIS TOGETHER}

Studying the response of both partners that are under stress, both anemones and algae, showed us how important each of them is to the other. If the algae do not cope well with the heat stress, the anemones will also suffer. Our results show us that the Red Sea anemones are not that different from the other anemones from cold water. Instead, they just get a little more help from their algae friends. We believe, since anemones and coral are related, that this result will hold true for corals, too. This shows how specific coral-algae partnerships can lead to a higher survival success for corals in warm water environments. 
By understanding the coral-algae relationship better, we can hopefully find ways to help coral reefs survive in the future.

\section{ORIGINAL SOURCE ARTICLE}

Cziesielski, M. J., Liew, Y. J., Cui, G., Schmidt-Roach, S., Campana, S., Marondedze, C., et al. 2018. Multi-omics analysis of thermal stress response in a zooxanthellate cnidarian reveals the importance of associating with thermotolerant symbionts. Proc. Biol. Sci. 285:20172654. doi: 10.1098/rspb.2017.2654

\section{REFERENCES}

1. Matthews, J. L., Crowder, C. M., Oakley, C. A., Lutz, A., Roessner, U., Meyer, E., et al. 2017. Optimal nutrient exchange and immune responses operate in partner specificity in the cnidarian-dinoflagellate symbiosis. Proc. Natl. Acad. Sci. U.S.A. 114:13194-9. doi: 10.1073/pnas.1710733114

2. Cziesielski, M. J., Liew, Y. J., Cui, G., Schmidt-Roach, S., Campana, S., Marondedze, C., et al. 2018. Multi-omics analysis of thermal stress response in a zooxanthellate cnidarian reveals the importance of associating with thermotolerant symbionts. Proc. Biol. Sci. 285:20172654. doi: 10.1098/ rspb.2017.2654

3. Downs, C. A., Fauth, J. E., Halas, J. C., Dustan, P., Bemiss, J., and Woodley, C. M. 2002. Oxidative stress and seasonal coral bleaching. Free Radic. Biol. Med. 33:533-43. doi: 10.1016/S0891-5849(02)00907-3

SUBMITTED: 18 November 2018; ACCEPTED: 06 February 2019; PUBLISHED ONLINE: 27 February 2019.

EDITED BY: Christian Robert Voolstra, King Abdullah University of Science and Technology, Saudi Arabia

CITATION: Cziesielski MJ and Aranda M (2019) With a Little Help From FriendsHow Algae Help Corals Survive Temperature Stress. Front. Young Minds 7:28. doi: 10.3389/frym.2019.00028

CONFLICT OF INTEREST STATEMENT: The authors declare that the research was conducted in the absence of any commercial or financial relationships that could be construed as a potential conflict of interest.

COPYRIGHT @ 2019 Cziesielski and Aranda. This is an open-access article distributed under the terms of the Creative Commons Attribution License (CC BY). The use, distribution or reproduction in other forums is permitted, provided the original author(s) and the copyright owner(s) are credited and that the original publication in this journal is cited, in accordance with accepted academic practice. No use, distribution or reproduction is permitted which does not comply with these terms. 

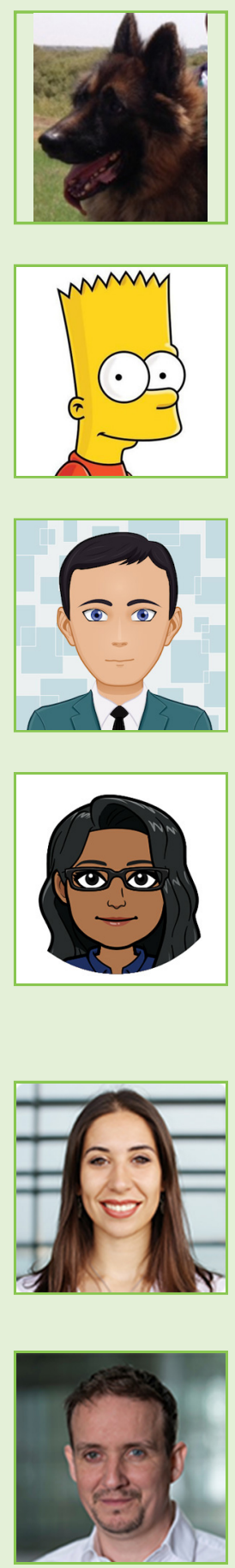

I am a final year Ph.D. student at the King Abdullah University of Science and Technology. I have been working what climate change does to coral's and the small algae that live in their cells. When I am not doing Science, I enjoy being physically active either at the gym, dancing, or outdoor activities. *maha.olschowsky@kaust.edu.sa

\section{MANUEL ARANDA}

I am a Biology Professor at the King Abdullah University of Science and Technology in Saudi Arabia. I study why corals are so sensitive to climate and how we might be able to help them. In my free time I like to cook and to play Playstation with my son. 